\title{
Potential risk factors for recurrent pulmonary embolism in hospitalized patients
}

\author{
Lu Wang, Wuwan Wang, Tingting Shu, Panpan Feng, Rui Xiang, Wei Huang \\ Department of Cardiology, the First Affiliated Hospital of Chongqing Medical University, Chongqing, China \\ Contributions: (I) Conception and design: L Wang, W Wang, W Huang; (II) Administrative support: W Huang; (III) Provision of study materials \\ or patients: L Wang, T Shu, W Wang; (IV) Collection and assembly of data: L Wang, W Wang; (V) Data analysis and interpretation: L Wang, W \\ Wang; (VI) Manuscript writing: All authors; (VII) Final approval of manuscript: All authors. \\ Correspondence to: Wei Huang, MD, PhD. Department of Cardiology, The First Affiliated Hospital of Chongqing Medical University, No. 1 Youyi \\ Road, Yuzhong District, Chongqing 400016, China. Email: weihuangcq@gmail.com.
}

\begin{abstract}
Backgroundk Pulmonary embolism (PE) recurrence is the primary factor affecting the prognoses of patients with venous thromboembolism (VTE). However, the major challenge physicians face in these patients is the possible risk of $\mathrm{PE}$ recurrence after treatment. Given that renal impairment is a significant predictor of mortality in cardiovascular diseases, this study aimed to examine the relationship between renal dysfunction and PE recurrence.

Methods: This study was retrospective analysis of the Medical Data Science Academy of Chongqing Medical University database. Patients primarily diagnosed with PE from January 1, 2017 to December 31, 2019 were included in the study. The patients were divided into two groups: the PE group and the recurrent PE group. They were screened based on the International Coding of Diseases (ICD) system and verified using computed tomography pulmonary angiography. Univariate analysis and multivariate logistic regression (MLR) analysis were used for predicting PE recurrence.

Results: Of the 365 PE patients included in the study, 55 (15.1\%) were recurrent patients. Estimated glomerular filtration rate (eGFR) was found to be closely associated with PE recurrence. MLR analysis yielded an odds ratio (OR) of 4.061 [95\% confidence interval (CI): 1.471-11.209, P=0.007] for recurrent PE. Conclusions: Renal dysfunction increases the risk of PE recurrence. Thus, clinicians should pay more attention to patients with $\mathrm{PE}$ and impaired renal function.
\end{abstract}

Keywords: Venous thromboembolism (VTE); pulmonary embolism (PE); risk factors; anticoagulants; renal dysfunction

Submitted Dec 23, 2020. Accepted for publication Jan 29, 2021.

doi: 10.21037/apm-21-36

View this article at: http://dx.doi.org/10.21037/apm-21-36

\section{Introduction}

Pulmonary embolism (PE), a form of venous thromboembolism (VTE), is the major cause of VTErelated death and accounts for approximately 100,000300,000 deaths annually $(1,2)$. PE recurrence is the primary factor affecting the prognoses of patients with VTE. The recurrent VTE fatality rate in patients with a previous history of $\mathrm{PE}$ is twice as high as the rate of VTE recurrence in patients with a previous history of deep vein thrombosis (DVT) $(3,4)$. PE recurrence decreases quality of life, prolongs hospitalization time, increases the risk of chronic thromboembolic pulmonary hypertension, and causes severe burden to patients and society $(5,6)$. Thus, the 2019 European Society of Cardiology clinical guidelines recommended a dose reduction in rivaroxaban or apixaban to prolong anticoagulation time after the initial 6 months of therapy. However, prolonging anticoagulation is associated with bleeding risk (7). Hence, the need for a better understanding of patients who are at an increased risk of 
developing PE recurrence and methods for decreasing risk factors has recently become more urgent (8).

Right ventricular dysfunction and hemodynamic instability have been identified as indicators of poor prognosis in patients with PE $(9,10)$. Impaired cardiac output, hypoxemia, and increased central venous pressure result in elevated venous pressure and decreased glomerular filtration and perfusion pressure. A reduction in estimated glomerular filtration rate (eGFR) may be a significant risk factor for increased mortality in patients with PE. We thus hypothesized that renal dysfunction is an independent marker of PE recurrence (11-13). To examine the magnitude of the effect of renal dysfunction on $\mathrm{PE}$ recurrence, we designed a population-based retrospective study in Southwestern China.

We present the following article in accordance with the STROBE reporting checklist (available at http://dx.doi. org/10.21037/apm-21-36).

\section{Methods}

\section{Overall study design}

The research was an analytical retrospective study of a continuous population sample and was carried out jointly with the China Data Process \& Application Platform (DPAP, Yidu-Cloud (Beijing) Technology Co., Ltd., China). We retrieved, de-identified, and utilized patient information from the database of the Medical Data Science Academy of Chongqing Medical University. The database included vital health information of patients from seven hospitals, with an estimated sample size of more than 3 million patients between January 1, 2017 and December 31, 2019. All the information on the platform was anonymous and had unique identify codes for privacy protection. The data were not open access (14).

Patients diagnosed with PE were screened based on the International Coding of Diseases (ICD) [PE: ICD-10 (I26.x)]. Computed tomography pulmonary angiography results were screened independently by two authors, who excluded studies that were not pertinent to diagnosis. Clinical and demographic data including sex, age, smoking history, surgical history, sign and symptoms, physical examination, predefined laboratory markers, medical therapies, and medical history, such as the absence or presence of predefined comorbidities and potential risk factors for the development of recurrent PE (including antiphospholipid syndrome, trauma or fracture history, and active cancer), were collected. Laboratory markers included C-reactive protein (CRP), d-dimer, international normalized ratio (INR), total cholesterol (TC), low-density lipoprotein cholesterol (LDL-C), and serum creatinine. Comorbidities included hypertension, atrial fibrillation (AFib), coronary heart disease (CHD), heart failure, diabetes mellitus, hyperlipidemia, stroke, DVT, chronic obstructive pulmonary disease (COPD), antiphospholipid syndrome, and multiple cancer (liver, lung, ovary, bladder, pancreas, laryngeal, and epityphlon; see Table S1 for the list of specific ICD codes). Data on medical treatments were also collected, including warfarin, antiplatelet (aspirin, clopidogrel, and ticagrelor), heparin (low-molecular-weight heparin, heparin, and nadroparin), and non-vitamin $\mathrm{K}$ antagonist oral anticoagulant (rivaroxaban, apixaban, and dabigatran) therapies. To minimize the effect of missing data, medical records were rechecked when any of the following occurred: follow-up by a medical provider; recurrent PE; arrival of December 31, 2019; or death. Missing data were considered to be missing at random. The study was conducted according to the guidelines of the Declaration of Helsinki (as revised in 2013) and approved by the First Affiliated Hospital of Chongqing Medical University Ethics Committee (no. 2020-282; date of approval: June 15, 2020). The Human Research Committee of Chongqing Medical University waived the need for informed consent.

\section{Definition}

Anticoagulation was defined as receiving any anticoagulant medication for more than 3 months. Recurrent PE was defined as any subsequent ICD-based diagnosis of PE occurring after the index event based on the ICD codes (8). The eGFR was estimated through the Chronic Kidney Disease Epidemiology Collaboration equation (CKD-EPI).

\section{Statistical analysis}

We conducted all statistical analyses with Stata/SE 15.1 (StataCorp LLC, College Station, TX, USA). Normally distributed continuous variables are represented by mean \pm SD, whereas non-normally distributed data are presented as median with interquartile range (IQR); qualitative variables are expressed as percentages. We investigated the utilization status of antithrombotic drugs in patients with $\mathrm{PE}$. The patients were divided into two groups (the PE and recurrence PE groups). Demographic data, clinical 
Table 1 Demographic and clinical characteristics of patients stratified by pulmonary embolism recurrence $v s$. non-recurrence

\begin{tabular}{|c|c|c|c|}
\hline Variable & No recurrence $(n=310)$ & Recurrence $(n=55)$ & $P$ value \\
\hline Age, y & $70.0(62.0-78.0)$ & $73.0(65.0-81.0)$ & 0.153 \\
\hline Male sex (\%) & 60.7 & 56.4 & $0.550^{a}$ \\
\hline \multicolumn{4}{|l|}{ Physical examination } \\
\hline Sitting DBP, mmHg & $76.0(69.0-85.0)$ & $80.0(72.0-87.0)$ & 0.222 \\
\hline Sitting pulse rate, beats per min & $90.0(78.0-103.0)$ & $88.0(79.0-100.0)$ & 0.999 \\
\hline \multicolumn{4}{|l|}{ Sign and symptoms } \\
\hline Dyspnea (\%) & 53 & 43.5 & $0.232^{a}$ \\
\hline Hemoptysis (\%) & 4.2 & 10.9 & $0.039^{\mathrm{a}}$ \\
\hline Swell (\%) & 21.3 & 21.8 & $0.930^{\mathrm{a}}$ \\
\hline \multicolumn{4}{|l|}{ Medical therapies } \\
\hline Anticoagulation (\%) & 97.4 & 89.1 & $0.003^{\mathrm{a}}$ \\
\hline Antiplatelet (\%) & 26.5 & 32.7 & $0.336^{a}$ \\
\hline Statin (\%) & 36.1 & 45.5 & $0.188^{\mathrm{a}}$ \\
\hline
\end{tabular}

Data are shown as medians with IQR for continuous variables with non-normal distribution and as $\mathrm{n}$ (\%) for categorical outcomes. $\mathrm{P}$ values were based on Wilcoxon rank-sum test for all continuous variables and Pearson's chi-squared test or Fisher's exact test for categorical variables. The test use in categorical variables are presented as ${ }^{a}$ for Pearson's chi-squared test and ${ }^{\mathrm{b}}$ for the Fisher's exact test. SBP, systolic blood pressure; DBP, diastolic blood pressure.

characteristics, baseline comorbidities, and laboratory markers of the groups were compared. A Shapiro-Wilk normality test was used to assess the normality of the distribution. The Wilcoxon rank-sum test was used for continuous variables while Pearson's chi-squared test or the Fisher's exact test was used for categorical variables. Variables with a $\mathrm{P}$ value $<0.2$ in the univariate analysis were included in the multivariate analysis. Multivariate logistic regression (MLR) analysis was used to predict the recurrence of $\mathrm{PE}$ using potential risk factors. We calculated the adjusted odds ratio (OR) for PE recurrence with $95 \%$ confidence intervals (CIs) (predictor variables of interest). A $\mathrm{P}$ value $<0.05$ was considered statistically significant.

\section{Results}

A total of 671 patients were retrieved from database based on ICD-code, while 365 patients diagnosed with PE diagnosed clinically and confirmed by radiographic evidence were included in the study, and the median follow-up period was 19.2 months [interquartile range (IQR), 10.626.2 months]. The recurrence of PE occurred in $15.1 \%$ $(55 / 365)$ of all patients over the study period, with a median time to recurrence of 3.6 months. Approximately $96 \%$ $(351 / 365)$ of the respondents were taking anticoagulant medication for more than 3 months. The results obtained from the preliminary analysis of demographic data, sign and symptoms, physical examination, and medical therapies are presented in Table 1. The proportion of patients with PE recurrence who presented with hemoptysis was significantly higher than that of patients who did not $(10.9 \%$ vs. $4.2 \%$, $\mathrm{P}=0.039)$. The recurrent patients who presented with hemoptysis also had lower anticoagulation use $(89.1 \%$ s. 97.4\%, $\mathrm{P}=0.003$ ). Of these 365 patients (16 missing eGFR data) in this research, 40 were with eGFR $<60 \mathrm{~mL} / \mathrm{min}$ per $1.73 \mathrm{~m}^{2}$. In these 40, only two were in CKD4 (eGFR $15-$ 
Table 2 Univariate analysis of relevant comorbidity and clinical data of patients stratified by pulmonary embolism recurrence $v s$. non-recurrence

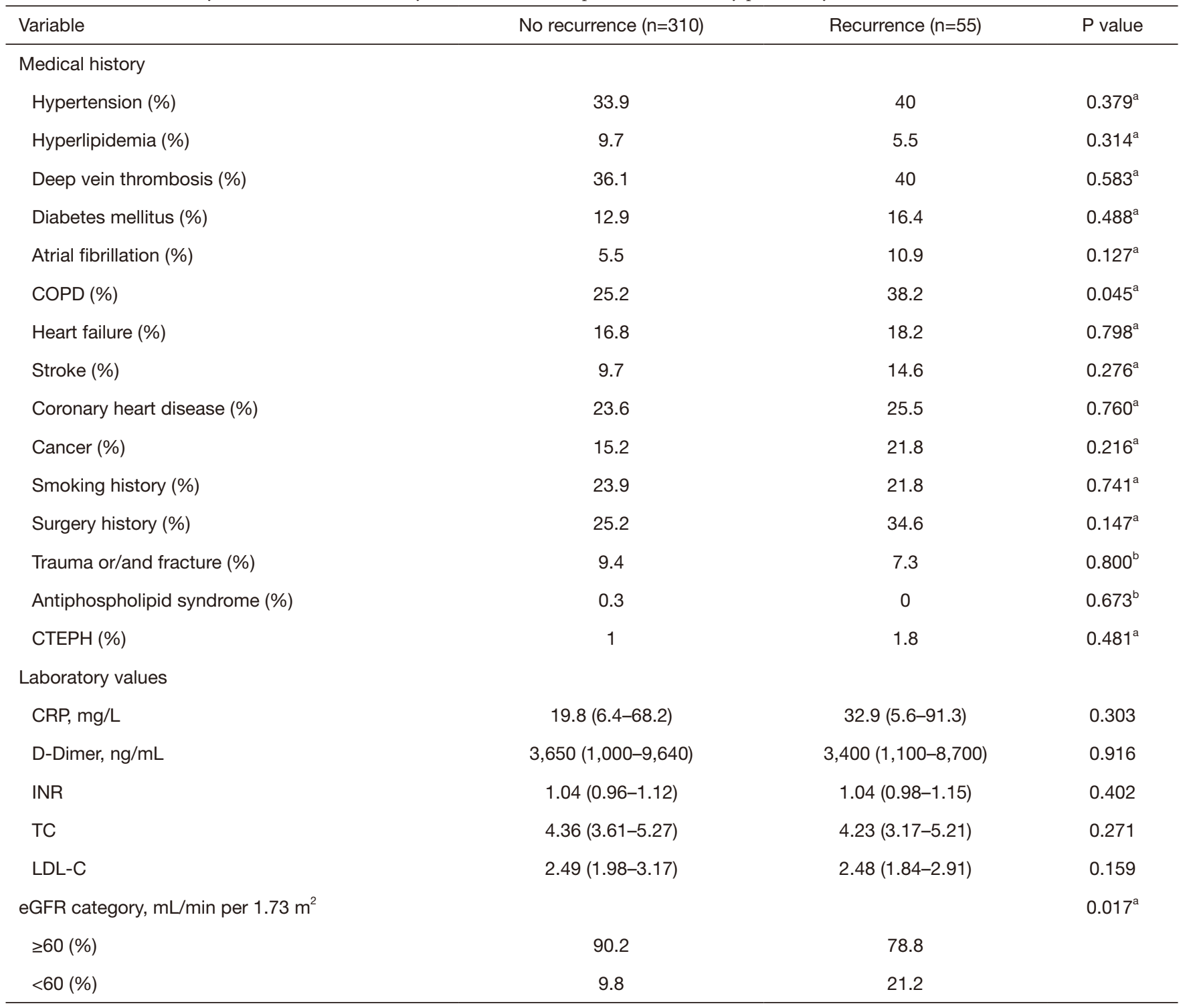

Data are shown as median with IQR for continuous variables with non-normal distribution and as $n$ (\%) for categorical outcomes. $\mathrm{P}$ values were based on Wilcoxon rank-sum test for continuous variables and Pearson's chi-squared test or Fisher's exact test for categorical variables. The test utilization in categorical variables are presented as ${ }^{a}$ for Pearson's chi-squared test and ${ }^{\mathrm{b}}$ for Fisher's exact test. COPD, chronic obstructive pulmonary disease; CTEPH, chronic thromboembolic pulmonary hypertension; CRP, C-reactive protein; INR, international normalized ratio; TC, total cholesterol; LDL-C, low-density lipoprotein cholesterol; eGFR, estimated glomerular filtration rate.

$29 \mathrm{~mL} / \mathrm{min}$ per $1.73 \mathrm{~m}^{2}$ ), while none were in CKD5 (eGFR $<15 \mathrm{~mL} / \mathrm{min}$ per $1.73 \mathrm{~m}^{2}$ ).

Table 2 displays the univariable analysis of relevant comorbidity and clinical data of patients stratified into PE recurrence $(n=55)$ and no $P E$ recurrence $(n=310)$. In the unadjusted model, a greater proportion of patients with $\mathrm{PE}$ recurrence had COPD (38.2\% vs. $25.2 \%, \mathrm{P}=0.045)$ and
eGFR $<60 \mathrm{~mL} / \mathrm{min}$ per $1.73 \mathrm{~m}^{2}(21.2 \%$ vs. $9.8 \%, \mathrm{P}=0.017)$ compared to the no PE recurrence patients.

We conducted a MLR analysis with PE recurrence as the dependent variable and included 10 independent predictor variables with a $\mathrm{P}$ value $<0.2$ in the univariate analysis including age, SBP, AFib, COPD, surgery history, anticoagulation use, statin 
Table 3 Multivariate logistic regression analysis with associated odds ratios for pulmonary embolism recurrence

\begin{tabular}{lcc}
\hline \multirow{2}{*}{ Variable } & \multicolumn{2}{c}{ Pulmonary embolism recurrence } \\
\cline { 2 - 3 } & P value & Odds ratios $(95 \% \mathrm{Cl})$ \\
\hline Age & 0.312 & $0.981(0.946-1.018)$ \\
SBP & 0.311 & $1.009(0.99-1.027)$ \\
Atrial fibrillation & 0.151 & $2.590(0.708-9.480)$ \\
COPD & 0.020 & $2.858(1.183-6.901)$ \\
Surgery history & 0.148 & $1.919(0.793-4.645)$ \\
EGFR <60 & 0.007 & $4.061(1.471-11.209)$ \\
(mL/min per 1.73 $\left.\mathrm{m}^{2}\right)$ & & $0.092(0.018-0.471)$ \\
Anticoagulation & 0.004 & $2.461(1.104-5.488)$ \\
Statin & 0.028 & $4.147(0.828-20.778)$ \\
Hemoptysis & 0.084 & $0.679(0.431-1.071)$ \\
\hline LDL-c & 0.096 &
\end{tabular}

SBP, systolic blood pressure; COPD, chronic obstructive pulmonary disease; eGFR, estimated glomerular filtration rate; LDL-C, low-density lipoprotein cholesterol.

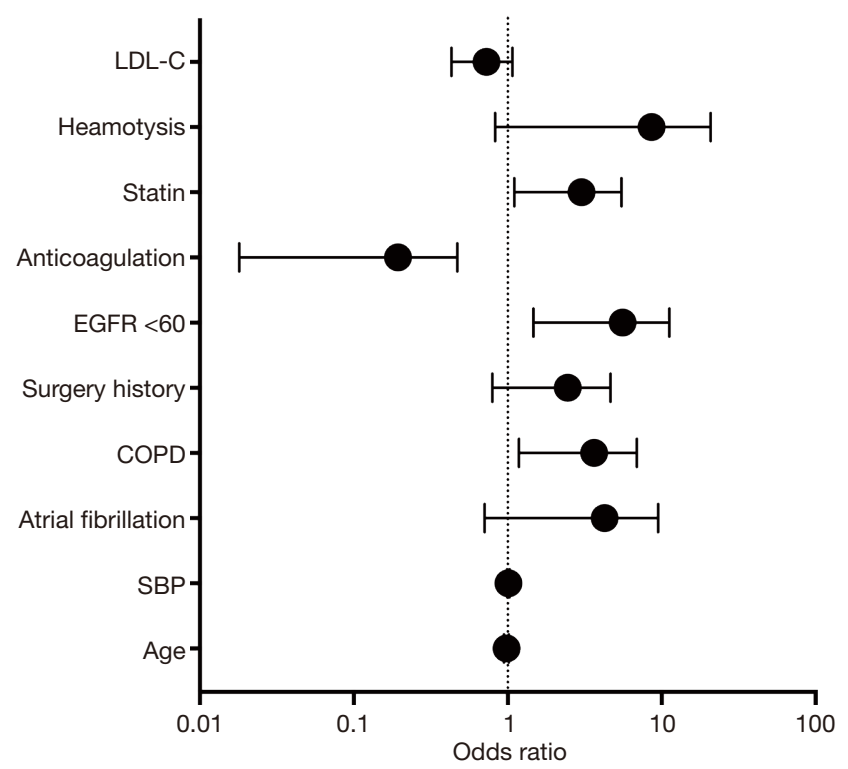

Figure 1 Adjusted odds ratios for pulmonary embolism recurrence from multivariate logistic regression analysis.

use, hemoptysis, LDL-c, and eGFR $<60 \mathrm{~mL} / \mathrm{min}$ per $1.73 \mathrm{~m}^{2}$. The results of the MLR analysis on the two groups are shown in Table 3, as well as visually in Figure 1. In the MLR analysis model, the significant independent parameters associated with recurrent $\mathrm{PE}$ were eGFR with levels of $<60 \mathrm{~mL} / \mathrm{min}$ per $1.73 \mathrm{~m}^{2}(\mathrm{OR}=4.061,95 \% \mathrm{CI}$, $1.471-11.209 ; \mathrm{P}=0.007)$, COPD $(\mathrm{OR}=2.858,95 \% \mathrm{CI}$, $1.183-6.901 ; \mathrm{P}=0.020)$, anticoagulation use $(\mathrm{OR}=0.092$, $95 \%$ CI, 0.018-0.471; $\mathrm{P}=0.004)$, and statin use $(\mathrm{OR}=2.461$, $95 \%$ CI, 1.104-5.488; $\mathrm{P}=0.028$ ).

\section{Discussion}

Our analysis of 365 patients with $\mathrm{PE}$ using a median followup period of 19.2 months indicated that eGFR $<60 \mathrm{~mL} / \mathrm{min}$ per $1.73 \mathrm{~m}^{2}$, along with a history of COPD, and anticoagulation and statin medication, is independently associated with a high risk of $\mathrm{PE}$ recurrence.

In patients with PE, VTE tends to recur similarly to PE. By contrast, patients who have DVT are inclined to suffer a relapse of DVT (15). Thus, the fatality recurrence rate of VTE in patients with a previous history of PE is twice as high as VTE recurrence after DVT $(3,4)$. However, the vast majority of randomized investigations on prolonged anticoagulation for VTE have included DVT patients with or without PE $(7,16,17)$. To the best of our knowledge, there are few related studies that solely focus on PE recurrence.

\section{Cbronic kidney disease (CKD)}

There have been several investigations into the relationship between CKD and the risk of VTE. Epidemiologic studies on VTE have reported an increased risk for VTE in patients receiving dialysis, and a series of autopsy studies have suggested that VTE-related events are common among patients with end-stage renal diseases (18-21). Moreover, the Longitudinal Investigation of Thromboembolism Etiology (LITE) study outlined a relative VTE risk of 1.7 (95\% CI: 1.2-2.5) for patients with stages III-IV CKD compared with patients with normal renal functions (21). Another study by the Prevention of REnal and Vascular ENd-stage Disease (PREVEND) clearly defined what "renal dysfunction" clinically means and suggested that CKDs are significant risk factors for VTE (22). However, studies investigating the relationship between PE recurrence and renal dysfunction are scarce. Nonetheless, our research findings support the previous studies which propose CKD as an indicator of poor prognosis in normotensive patients with PE (23-28). A prospective multicenter study, El Registro Informatizado de Pacientes con Enfermedad TromboEmbólica (RIETE) showed that patients with a creatinine clearance $(\mathrm{CrCl})$ of $<30 \mathrm{~mL} / \mathrm{min}$ had an increased incidence for lethal PE, 
bleeding, and even death compared with patients with a $\mathrm{CrCl}$ of $>30 \mathrm{~mL} / \mathrm{min}$ (26). The investigators of the study emphasized that in renal dysfunction patients with $\mathrm{PE}$ the main threat is PE itself. On the contrary, in those with DVT, the main threat is bleeding.

Although the mechanism is unclear at present, an initial observation suggests that there may be a link between hemostatic factors and CKD (29). von Willebrand factor and factor VIII are known markers for endothelial damage and may explain the increased risk of VTE associated with impaired kidney function (30). CKD, which is associated with endothelial damage, may lead to increased levels of von Willebrand factor and factor VIII, and eventually, venous thrombosis.

There is another mechanism that might explain the potential relationship between CKD and VTE. Previous studies have established that proteinuria is associated with venous thrombosis. In our attempt to explain those CKD patients with an increased risk of $\mathrm{PE}$ recurrence from proteinuria, we retrieved qualitative test information for proteinuria in these participants from the database. The recurrent patients had a significantly higher incidence of proteinuria than the no recurrence patients $(43.4 \%$ vs. $29.1 \%, P=0.040)$. This phenomenon may be explained by the loss of antithrombin in the urine; however, clarifying this mechanism was beyond the scope of our study. Ultimately, our study results add to the existing evidence (a prediction model for PE recurrence) supporting the role of renal dysfunction in $\mathrm{PE}$ recurrence.

\section{COPD}

We found that PE-recurrence was associated with COPD. However, the mechanism underlying remain less welldefined. A previous systematic review was performed to determine the reported prevalence of $\mathrm{PE}$ in acute exacerbations of COPD. Among the 550 patients with COPD exacerbation, the prevalence of PE was $19.9 \%$ (95\% CI, 6.7\% to $33.0 \%$; $\mathrm{P}=0.014$ ). However, an important limitation of the study was its inability to determine whether the PE was the cause of the COPD exacerbation, a result of the COPD exacerbation, or a mere coincidence. Likewise, the same problem also exists with our results. Nonetheless, it was not within the scope of this study to determine the reasons behind this phenomenon.

\section{Anticoagulation and adjuvant therapy}

Although oral anticoagulant therapy is undoubtedly useful in decreasing the risk of VTE during therapy, it is not helpful after the cessation of therapy, irrespective of therapy duration (3). According to current guidelines, extended or indefinite anticoagulation is recommended for patients with an unprovoked PE due to the increased risk of recurrence and the life-threatening consequences of a recurrent event (31). Trials on the treatment of acute VTE, as well as those on extended treatment beyond the first 6 months, demonstrated that different anticoagulant treatments have a similar prophylaxis efficacy of $\mathrm{PE}$ recurrence except antiphospholipid syndrome $(32,33)$. However, anticoagulation inevitably increases the risk of major bleeding (34). Thus, practical predictive models and safer therapeutic options are needed. Meanwhile, statin may be considered as adjuvant therapy in the prevention of PE recurrence. Moreover, two previous published studies with a total of 1,224 patients, extended therapy with aspirin after a standard oral anticoagulation was associated with a $30-35 \%$ reduction in the risk of recurrence compared with placebo $(35,36)$. In addition, a randomized, placebo-controlled study suggested that sulodexide given after anticoagulation reduced the risk of recurrence in patients with unprovoked venous thromboembolism, with no apparent increase of bleeding risk (37). Further research is required to corroborate these findings.

Furthermore, the anticoagulant gene polymorphisms may have implications for reducing the risk of bleeding. For example, the genetic polymorphisms of the CES such as CES1 SNP rs8192935, CES1 SNP rs2244613, CES1 SNP rs71647871 may cause the decrease of the plasma concentration, which may lead to bleeding events (38-40). More studies are needed to confirm the role of polymorphisms in genes.

\section{Clinical significance}

The results of our current study suggested that clinicians should be more sensitive to the recurrence of $\mathrm{PE}$ in patients with confirmed $\mathrm{PE}$ and impaired renal function. According to the 2019 ESC guideline, a reduced dose of anticoagulants for extended the duration of anticoagulation should be considered for patients with a persistent risk factor other than antiphospholipid antibody syndrome (7). The duration 
of anticoagulation in these patients can be extended appropriately, assuming no contraindications. However, the eGFR $\leq 60 \mathrm{~mL} / \mathrm{min} / 1.73 \mathrm{~m}^{2}$ independently predicted higher 30- and 180-day all-cause mortality and bleeding events. Further research on balancing the increased bleeding risk associated with impaired renal function and the course of anticoagulants is needed.

\section{Study limitations}

We acknowledge that there were some limitations in our study. First, screening for the inclusion of patients depended on the ICD code. Previous studies have shown that ICD coding cannot comprehensively identify all cases and yielded a positive predictive value of $49 \%$ for VTE (41). Second, some pieces of essential information are missing in our database. Given the potential limitations in the scope of access of our database to outpatient follow-up prescription data, it is possible that a portion of patients with no anticoagulation therapy actually received anticoagulants that were not captured in this analysis. And this could also occur if patients received care out of the Southwestern China or out-of-network, leading to missing data. Third, although some additional adjuvant therapies were considered, such as statin and aspirin, which are known to be useful in decreasing the risk of PE recurrence, a discrepancy in anticoagulation therapy duration between the groups might have affected the results. Furthermore, due to inadequate data, the PE recurrence could not be stratified according to the complex etiology and severity in the present study. Moreover, due to the inconsistent results, whether this active treatment of right ventricular dysfunction conveys a meaningful clinical benefit will require further investigation. Nevertheless, our research was a multicenter, real-world study with a long-term follow-up that produced promising results, and PE recurrence among patients living with renal dysfunction needs further attention from clinicians.

\section{Conclusions}

The results showed that renal dysfunction is associated with PE recurrence. Despite the relatively limited sample size used in this study, our work offers valuable insights into the implications of optimizing forecasting models. Studies with larger sample sizes that investigate the related mechanisms are still needed.

\section{Acknowledgments}

The authors thank Yiducloud (Chongqing) Technology Co., Ltd. and the cooperative Medical Data Science Academy of Chongqing Medical University for their contribution to the data collection and the Department of Computer Technology for their hard work on data management. Funding: None.

\section{Footnote}

Reporting Checklist: The authors have completed the STROBE reporting checklist. Available at http://dx.doi. org/10.21037/apm-21-36

Data Sharing Statement: Available at http://dx.doi. org/10.21037/apm-21-36

Conflicts of Interest: All authors have completed the ICMJE uniform disclosure form (available at http://dx.doi. org/10.21037/apm-21-36). The authors have no conflicts of interest to declare.

Ethical Statement: The authors are accountable for all aspects of the work in ensuring that questions related to the accuracy or integrity of any part of the work are appropriately investigated and resolved. The study was conducted according to the guidelines of the Declaration of Helsinki (as revised in 2013) and approved by the First Affiliated Hospital of Chongqing Medical University Ethics Committee (no. 2020-282; date of approval: June 15, 2020). The Human Research Committee of Chongqing Medical University waived the need for informed consent.

Open Access Statement: This is an Open Access article distributed in accordance with the Creative Commons Attribution-NonCommercial-NoDerivs 4.0 International License (CC BY-NC-ND 4.0), which permits the noncommercial replication and distribution of the article with the strict proviso that no changes or edits are made and the original work is properly cited (including links to both the formal publication through the relevant DOI and the 
license). See: https://creativecommons.org/licenses/by-nc$\mathrm{nd} / 4.0 /$.

\section{References}

1. Cohen AT, Agnelli G, Anderson FA, et al. Venous thromboembolism (VTE) in Europe. The number of VTE events and associated morbidity and mortality. Thromb Haemost 2007;98:756-64.

2. Horlander KT, Mannino DM, Leeper KV. Pulmonary embolism mortality in the United States, 1979-1998: an analysis using multiple-cause mortality data. Arch Intern Med 2003;163:1711-7.

3. Carrier M, Le Gal G, Wells PS, et al. Systematic review: case-fatality rates of recurrent venous thromboembolism and major bleeding events among patients treated for venous thromboembolism. Ann Intern Med 2010;152:578-89.

4. Douketis JD, Gu CS, Schulman S, et al. The risk for fatal pulmonary embolism after discontinuing anticoagulant therapy for venous thromboembolism. Ann Intern Med 2007;147:766-74.

5. Klok FA, van Kralingen KW, van Dijk AP, et al. Quality of life in long-term survivors of acute pulmonary embolism. Chest 2010;138:1432-40.

6. Lang IM, Pesavento R, Bonderman D, et al. Risk factors and basic mechanisms of chronic thromboembolic pulmonary hypertension: a current understanding. Eur Respir J 2013;41:462-8.

7. Konstantinides SV, Meyer G, Becattini C, et al. 2019 ESC Guidelines for the diagnosis and management of acute pulmonary embolism developed in collaboration with the European Respiratory Society (ERS): The Task Force for the diagnosis and management of acute pulmonary embolism of the European Society of Cardiology (ESC). Eur Respir J 2019;54:1901647.

8. Stewart LK, Sarmiento EJ, Kline JA. Statin Use is Associated with Reduced Risk of Recurrence in Patients with Venous Thromboembolism. Am J Med 2020;133:930-935.e8.

9. ten Wolde M, Söhne M, Quak E, et al. Prognostic value of echocardiographically assessed right ventricular dysfunction in patients with pulmonary embolism. Arch Intern Med 2004;164:1685-9.

10. Grifoni S, Vanni S, Magazzini S, et al. Association of persistent right ventricular dysfunction at hospital discharge after acute pulmonary embolism with recurrent thromboembolic events. Arch Intern Med
2006;166:2151-6.

11. Al Suwaidi J, Reddan DN, Williams K, et al. Prognostic implications of abnormalities in renal function in patients with acute coronary syndromes. Circulation 2002;106:974-80.

12. Gibson CM, Pinto DS, Murphy SA, et al. Association of creatinine and creatinine clearance on presentation in acute myocardial infarction with subsequent mortality. J Am Coll Cardiol 2003;42:1535-43.

13. Damman K, Navis G, Voors AA, et al. Worsening renal function and prognosis in heart failure: systematic review and meta-analysis. J Card Fail 2007;13:599-608.

14. Wang W, Wang L, Feng P, et al. Real-world in-hospital outcomes and potential predictors of heart failure in primigravid women with heart disease in Southwestern China. BMC Pregnancy Childbirth 2020;20:372.

15. Murin S, Romano PS, White RH. Comparison of outcomes after hospitalization for deep venous thrombosis or pulmonary embolism. Thromb Haemost 2002;88:407-14.

16. Couturaud F, Sanchez O, Pernod G, et al. Six Months vs Extended Oral Anticoagulation After a First Episode of Pulmonary Embolism: The PADIS-PE Randomized Clinical Trial. Jama 2015;314:31-40.

17. Agnelli G, Prandoni P, Becattini C, et al. Extended oral anticoagulant therapy after a first episode of pulmonary embolism. Ann Intern Med 2003;139:19-25.

18. Wiesholzer M, Kitzwögerer M, Harm F, et al. Prevalence of preterminal pulmonary thromboembolism among patients on maintenance hemodialysis treatment before and after introduction of recombinant erythropoietin. Am J Kidney Dis 1999;33:702-8.

19. Stein PD, Henry JW. Prevalence of acute pulmonary embolism among patients in a general hospital and at autopsy. Chest 1995;108:978-81.

20. Tveit DP, Hypolite IO, Hshieh P, et al. Chronic dialysis patients have high risk for pulmonary embolism. Am J Kidney Dis 2002;39:1011-7.

21. Wattanakit K, Cushman M, Stehman-Breen C, et al. Chronic kidney disease increases risk for venous thromboembolism. J Am Soc Nephrol 2008;19:135-40.

22. Ocak G, Verduijn M, Vossen CY, et al. Chronic kidney disease stages 1-3 increase the risk of venous thrombosis. J Thromb Haemost 2010;8:2428-35.

23. Goldhaber SZ, Visani L, De Rosa M. Acute pulmonary embolism: clinical outcomes in the International Cooperative Pulmonary Embolism Registry (ICOPER). Lancet 1999;353:1386-9. 
24. Conget F, Otero R, Jiménez D, et al. Short-term clinical outcome after acute symptomatic pulmonary embolism. Thromb Haemost 2008;100:937-42.

25. Kostrubiec M, Pruszczyk P, Bochowicz A, et al. Biomarkerbased risk assessment model in acute pulmonary embolism. Eur Heart J 2005;26:2166-72.

26. Falgá C, Capdevila JA, Soler S, et al. Clinical outcome of patients with venous thromboembolism and renal insufficiency. Findings from the RIETE registry. Thromb Haemost 2007;98:771-6.

27. Kostrubiec M, Łabyk A, Pedowska-Włoszek J, et al. Assessment of renal dysfunction improves troponin-based short-term prognosis in patients with acute symptomatic pulmonary embolism. J Thromb Haemost 2010;8:651-8.

28. Kostrubiec M, Łabyk A, Pedowska-Włoszek J, et al. Neutrophil gelatinase-associated lipocalin, cystatin $\mathrm{C}$ and eGFR indicate acute kidney injury and predict prognosis of patients with acute pulmonary embolism. Heart 2012;98:1221-8.

29. Benotti JR, Dalen JE. The natural history of pulmonary embolism. Clin Chest Med 1984;5:403-10.

30. Ocak G, Vossen CY, Lijfering WM, et al. Role of hemostatic factors on the risk of venous thrombosis in people with impaired kidney function. Circulation 2014;129:683-91.

31. Kamphuisen PW, Eikenboom JC, Bertina RM. Elevated factor VIII levels and the risk of thrombosis. Arterioscler Thromb Vasc Biol 2001;21:731-8.

32. van Es N, Coppens M, Schulman S, et al. Direct oral anticoagulants compared with vitamin $\mathrm{K}$ antagonists for acute venous thromboembolism: evidence from phase 3 trials. Blood 2014;124:1968-75.

33. van der Hulle T, Kooiman J, den Exter PL, et al. Effectiveness and safety of novel oral anticoagulants as compared with vitamin $\mathrm{K}$ antagonists in the treatment of acute symptomatic venous thromboembolism: a

Cite this article as: Wang L, Wang W, Shu T, Feng P, Xiang R, Huang W. Potential risk factors for recurrent pulmonary embolism in hospitalized patients. Ann Palliat Med 2021;10(2):2134-2142. doi: 10.21037/apm-21-36 systematic review and meta-analysis. J Thromb Haemost 2014;12:320-8.

34. Kearon C, Kahn SR, Agnelli G, et al. Antithrombotic therapy for venous thromboembolic disease:

American College of Chest Physicians EvidenceBased Clinical Practice Guidelines (8th Edition). Chest 2008;133:454s-545s.

35. Brighton TA, Eikelboom JW, Mann K, et al. Low-dose aspirin for preventing recurrent venous thromboembolism. N Engl J Med 2012;367:1979-87.

36. Becattini C, Agnelli G, Schenone A, et al. Aspirin for preventing the recurrence of venous thromboembolism. N Engl J Med 2012;366:1959-67.

37. Andreozzi GM, Bignamini AA, Davì G, et al. Sulodexide for the Prevention of Recurrent Venous Thromboembolism: The Sulodexide in Secondary Prevention of Recurrent Deep Vein Thrombosis (SURVET) Study: A Multicenter, Randomized, Double-Blind, Placebo-Controlled Trial. Circulation 2015;132:1891-7.

38. Paré G, Eriksson N, Lehr T, et al. Genetic determinants of dabigatran plasma levels and their relation to bleeding. Circulation 2013;127:1404-12.

39. Dimatteo C, D'Andrea G, Vecchione G, et al. Pharmacogenetics of dabigatran etexilate interindividual variability. Thromb Res 2016;144:1-5.

40. Shi J, Wang X, Nguyen JH, et al. Dabigatran etexilate activation is affected by the CES1 genetic polymorphism G143E (rs71647871) and gender. Biochem Pharmacol 2016;119:76-84.

41. Al-Ani F, Shariff S, Siqueira L, et al. Identifying venous thromboembolism and major bleeding in emergency room discharges using administrative data. Thromb Res 2015;136:1195-8.

(English Language Editor: J. Gray) 


\section{Supplementary}

Table S1 The specific ICD codes used in defining variables

\begin{tabular}{|c|c|}
\hline Variable name & Variable description/coded values \\
\hline Age & Age of patient at the time of the pulmonary embolism \\
\hline Sex & $0=$ female $\mid 1=$ male $\mid$ null = unknown \\
\hline Pulmonary embolism & $\begin{array}{l}\text { ICD codes include I26.* (any diagnosis code that starts with I.26 indicates pulmonary embolism); } 1= \\
\text { positive } \mid 0=\text { negative }\end{array}$ \\
\hline Hyperlipidemia & ICD codes include E78.0*, E78.5*, R77.800*; $1=$ positive $\mid 0=$ negative \\
\hline DVT & ICD codes include $180.1^{\star}, 180.2^{*}, 180.3^{*}, 182.2^{*}, 182.8^{*}, 182.9^{*} ; 1=$ positive $\mid 0=$ negative \\
\hline Diabetes mellitus & ICD codes include E11.1*, E11.2*, E11.4*, E11.9*, E14.9*; $1=$ positive $\mid 0=$ negative \\
\hline Stroke & ICD codes include $160.9^{\star}, 163.8^{\star}, 163.9^{\star}, 164 . X^{\star}, 169.1^{*}, 169.3^{*}, 169.4^{*} ; 1=$ positive $\mid 0=$ negative \\
\hline CAD & ICD codes include I21. $1^{\star}, \mathrm{I} 25.1^{\star}, \mathrm{I} 25.5^{\star}, \mathrm{I} 24.9^{*} ; 1=$ positive $\mid 0=$ negative \\
\hline Renal dysfunction & 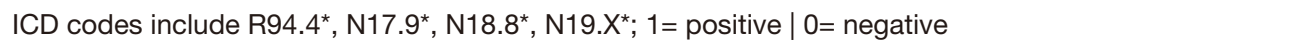 \\
\hline Cancer & 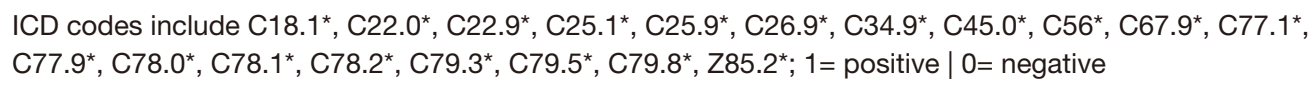 \\
\hline Trauma and/or fracture & 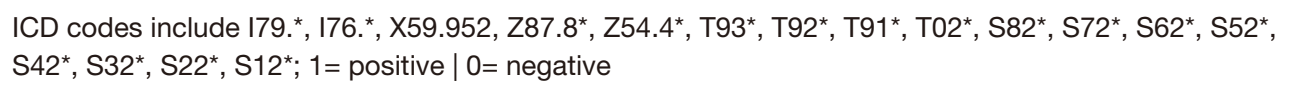 \\
\hline Antiphospholipid syndrome & ICD codes include $\mathrm{R} 79.801 ; 1=$ positive $\mid 0=$ negative \\
\hline
\end{tabular}

*, any diagnosis code that starts with the code before * indicates the variable. CAD, coronary artery disease; COPD, chronic obstructive pulmonary disease. 